\title{
Sistem Pendukung Keputusan Rekomendasi Emiten Saham Menggunakan Metode Simple Additive Weighting
}

\author{
Renny Puspita Sari", Muhamad Rabil Maulana \\ Fakultas Matematika dan Ilmu Pengetahuan Alam, Sistem Informasi, Universitas Tanjungpura, Pontianak, Indonesia \\ Email: 1,* rennysari.untan@gmail.com, ${ }^{2}$ rabilmaulana95@gmail.com \\ Submitted: 11/05/2021; Accepted: 27/05/2021; Published: 30/05/2021
}

\begin{abstract}
Abstrak-Pada era sekarang investasi saham merupakan instrumen yang sedang banyak digemari oleh kawula muda Indonesia, investasi saham merupakan satu dari banyak pilihan investasi yang semakin diminati oleh berbagai kalangan. Investasi saham merupakan kegiatan menahan diri dari kenikmatan saat ini demi kenikmatan yang lebih di masa yang akan datang, tak jarang invetasi ini membawa seseorang menjadi lebih bijak dalam mengatur keuangannya, memilih saham yang bagus bukanlah hal yang mudah bagi sebagian investor dibutuhkan banyak faktor dan rasio - rasio keuangan untuk memilih saham yang sekiranya dapat memberikan keutuangan yang sesuai dengan tujuan awal investasi. Oleh karena itu dibutuhkan sistem untuk membantu permasalahan tersebut. Sistem tersebut berupa sistem pendukung keputusan yang dapat membantu dalam mengambil keputusan dari pilihan-pilihan yang tersedia. Sistem Pendukung Keputusan Rekomendasi Emiten Saham Menggunakan Metode Simple Additive Weighting ini hadir untuk membantu dalam pemberi keputusan untuk memilih emiten atau saham yang bagus untuk di koleksi sehingga dapat memberi keuntungan yang baik dimasa yang akan datang. Hasil dari perhitungan pada sistem menggunakan metode SAW akan menampilkan rekomendasi saham terbaik yang cocok untuk pengguna berdasarkan data yang mereka masukkan.
\end{abstract}

Kata Kunci: Investasi; Keuangan; Saham; Simple Addictive Weighting; Rekomendasi

\begin{abstract}
In the current era, stock investing is an instrument that is currently popular with Indonesian youth, stock investing is one of the many investment options that are increasingly in demand by various groups. Investing in stocks is an activity to refrain from enjoying the present for more enjoyment in the future, this investment often brings someone to be wiser in managing their finances, choosing good stocks is not an easy thing for some investors it takes many factors and ratios - financial ratios to choose stocks that can provide financing by the initial investment objectives. Therefore we need a system to help these problems. The system is a decision support system that can assist in making decisions from the available options. This Stock Issuer Recommendation Decision Support System Using the Simple Additive Weighting Method is here to assist decisionmakers to choose good issuers or stocks to collect so that they can provide good profits in the future. The results of the calculation on the system using the Simple Additive Weighting method will show the best suitable stock recommendations for the user based on the data they enter.
\end{abstract}

Keywords: Finance; Investment; Recommendation; Simple Addictive Weighting; Stock

\section{PENDAHULUAN}

Pada era sekarang investasi saham merupakan instrumen yang sedang banyak digemari oleh kawula muda Indonesia, investasi saham merupakan satu dari banyak pilihan investasi yang semakin diminati oleh berbagai kalangan[1]. Banyak artis - artis maupun influenser yang berlomba - lomba mengajak pengikutnya untuk melakukan investasi pada pasar modal Indonesia ini, tentu saja fenomena tersebut sangat baik bagi pasar modal Indonesia tersendiri, kenaikan jumlah investor ini juga harus diimbangi dengan edukasi yang baik bagi para investor tersebut. Banyak para investor baru ini melakukan perdagangan saham hanya berdasarkan insting dan rekomendasi oleh berbagai macam pihak tanpa tau alasan dibalik itu, bukannya memberi keuntungan yang besar tapi malah kerugian yang mereka perole, investasi merupakan suatu langkah seseorang dalam pemenuhan kebutuhan di masa yang akan datang[2].

Baru - baru ini banyak berita yang memberitakan tentang hal - hal yang terkait dengan pasar modal Indonesia, seperti para investor saham yang melakukan perdagangan menggunakan uang pijaman online yang akhirnya malah menjadi hutang ada juga investor saham yang membeli saham berdasarkan ikut - ikutan kata orang yang malah menyebabkan kerugian.Investor juga harus berhati - hati terhadap saham yang terindikasi dikendalikan oleh bandar saham, bandar saham bisa mengendalikan harga pasar seperti menguasai supply saham[3]. Permainan bandar saham juga menjadi perbincangan yang hangat, dimana banyak memakan korban bagi para ritel yang tidak tau apa - apa, mereka membeli suatu saham dikarenakan di iming - imingi return yang besar di kemudian hari atau biasa disebut dipom - pom ada juga ritel yang takut kehilangan moment atau FOMO mereka tanpa pikir panjang membeli saham tanpa mengetahui apa yang mereka beli yang menyebabkan kerugian juga. Informasi yang minim di masyarakat mengenai pemilihan investasi yang ideal menyebabkan pengambilan keputusan yang kurang baik dan tidak tepat sehingga menghasilkan portofolio yang merugikan[4].

Polemik ini juga yang menyebabkan para investor yang baru bergabung pada bursa modal indonesia ini menjadi tidak betah dan akhirnya keluar lalu mencap bahwa berinvestasi saham ini merupakan kegiatan yang merugikan, padahal merekalah yang kurang memahami dalam berinvestasi. Untuk mengatasi hal itu ada baiknya para investor baru ini untuk melakukan analisa mereka sendiri ada banyak strategi analisa saham seperti growth investing atau value investing yang penulis gunakan pada penelitian ini, value investing pertama kali dikemukakan oleh Benjamin Graham seorang investor terkemuka pada jamannya yang juga menjadi gurunya Warren Buffet, 
mereka menjadikan value investing ini sebagai pedomannya untuk menentukan saham yang layak untuk dikoleksi. Pemanfaatan sistem pendukung keputusan yang tepat, akan membantu investor dalam menentukan keputusan terbaik yang dapat diambil sehingga dapat memaksimalkan keuntungan yang bisa didapatkan dalam pembelian saham dan mengurangi resiko yang mungkin terjadi[5].

Pada strategi value investing ini terdapat beberapa pertimbangan dalam menscreening emiten saham yaitu dengan menggunakan ratio keuangan seperti Price to Earning Ratio (PER), Price to Book Value (PBV), Return on Equity (ROE), Earning per Share (EPS), Dividend Payout Ratio (DPR), dan Dividend Yield (DY). Ada berbagai macam sector pada Bursa Efek Indonesia seperti sector agri, mining, property, finance, basic industry and chemicals, miscellaneous industry, consumer, trade, dan infrastruc pada penelitian ini penulis mengambil sector finance sebagai sample penelitian dengan kode emiten BBCA, BBNI, BMRI, BRRI, dan Mega. Ke 5 saham tersebut adalah 5 saham besar yang ada di sector finance sehingga penulis pilih untuk di analisis pada penelitian ini.

Berdasarkan penelitian yang dilakukan oleh Ratna Kusumawardani dan Achmad Solichin dengan judul "Implementasi Metode Simple Additve Weghting (Saw) Pada Sistem Pendukung Keputusan Untuk Menyeleksi Saham Prima" penelitian tersebut membahas tentang saham prima tetapi dengan kriteria yang basic.

Penulis menyempurnakan penelitian sebelumnya dengan menggunakan kriteria yang lebih mendalam yaitu dengan menggunakan rasio keuangan yang berfokus pada value atau nilai intrinsik dari perusahaan tersebut. Pada penelitian ini penulis memilih menggunakan Metode Simple Additive Weighting dimana dengan menggunakan metode Simple Additve Weighting ini penulis dapat menentukan nilai bobot dari setiap atribut yang ada lalu di lanjutkan dengan proses penentuan ranking oleh alternatif yang ada, hasil dari perangkingan inilah didapatkan alternatif terbaik yang akan menjadi rekomendasi dari penelitian ini. Atas dasar latar belakang tersebut maka dari itu penulis melakukan analisa penilitian dengan judul topik "Sistem Pendukung Keputusan Rekomendasi Emiten Saham Menggunakan Metode Simple Additive Weighting" yang sekiranya dapat membantu investor dalam pemilihan emiten saham.

\section{METODE PENELITIAN}

\subsection{Tahapan Penelitian}

Tahapan penelitian dimulai dari pengumpulan data, data dikumpulkan menggunakan metode survei dengan menyebarkan kuesioner menggunakan Google Form. Hasil data yang didapat dari Google Form selanjutnya akan dilakukan proses normalisasi data untuk membersihkan data-data yang tidak relevan dengan penelitian. Proses normalisasi ini dilakukan untuk memudahkan dalam menganasis data. Setelah dilakukan normalisasi, data-data tersebut dianalisis untuk menentukan kebutuhan sistem yang akan dikembangkan. Setelah dilakukan analisis, data tersebut diujikan dengan menggunakan perhitungan pada metode SAW. Hasil dari perhitungan SAW akan memberikan peringkat terhadap alternatif yang dimasukkan oleh pengguna. Selanjutnya, tahap akhir dari penelitian adalah proses dokumentasi dengan menyusun laporan dari hasil penelitian yang telah dilakukan. Gambaran dari tahapan penelitian dapat dilihat pada gambar 1 berikut ini.

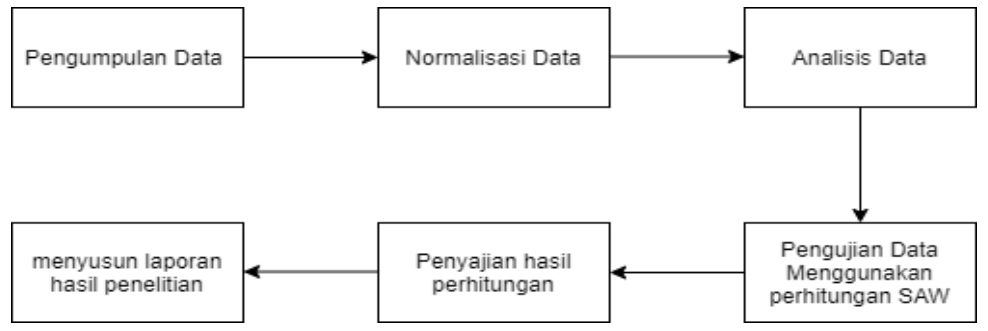

Gambar 1. Tahapan Penelitian

\subsection{Sistem Pendukung Keputusan}

Sistem Pendukung Keputusan (Decision Support System) adalah suatu sistem yang dapat memberikan kemudahan atau kemampuan, kepada pengguna sebagai solusi untuk memecahkan satu masalah yang rumit dengan cara terstruktur maupun tidak terstruktur[6]. Sistem pendukung keputusan sudah cukup banyak digunakan dalam membuat keputusan atas masalah - masalah tertentu seperti kenaikan gaji, penerimaan beasiswa, memilih jurusan, dan lain - lain[7]-[9]. Maka dari pengertian tersebut dapat di artikan SPK sebagai alat yang dapat digunakan untuk membantu dalam pengambilan keputusan terhadap suatu masalah.

\subsection{Metode Simple Additive Weighting}

Konsep dasar Simple Additive Weighting (SAW) adalah mencari penjumlahan terbobot dari rating kinerja pada setiap alternatif pada suatu kriteria, metode SAW membutuhkan proses normalisasi matrix keputusan (X) kesuatu skala yang dapat diperbandingkan dengan semua rating alternatif yang ada[10]. Metode SAW mengenal adanya 2 
(dua) atribut yaitu kriteria keuntangan (benefit) dan kriteria biaya (cost) [11]. Dengan Metode Simple Additive Weighting maka akan di dapatkan nilai bobot dari setiap kriteria yang lalu di lanjutkan dengan proses penentuan ranking dari setiap alternatif yang dimana alternatif dengan nilai ranking tertinggi akan menjadi rekomendasi dari sistem ini.Metode ini membutuhkan proses normalisasi matriks keputusan kedalam skala yang dapat diperbandingkan dengan semua rating alternatif yang ada[12]. Alternatif yang digunakan berupa 5 emiten pada sector baking yaitu adalah : Bank Central Asia (BBCA), Bank Negara Indonesia (BBNI), Bank Rakyat Indonesia (BBRI), Bank Mandiri (BMRI), dan Bank Mega (MEGA). Kriteria yang penulis gunakan dalam metode ini antara lain adalah PER (C1), PBV (C2), ROE (C3), EPS (C4), DPR (C5), DY (C6), penulis menentukan kriteria dengan cara menyebarkan kuesioner menggunakan google form pada mahasiswa dan alumnus Fakultas Matematika dan Ilmu Pengetahuan Alam Universitas Tanjungpura.

Secara umum, tahapan dari metode Simple Addictive Weighting mulai dari tahap masukkan data hingga memberikan hasil perhitungan adalah sebagai berikut:

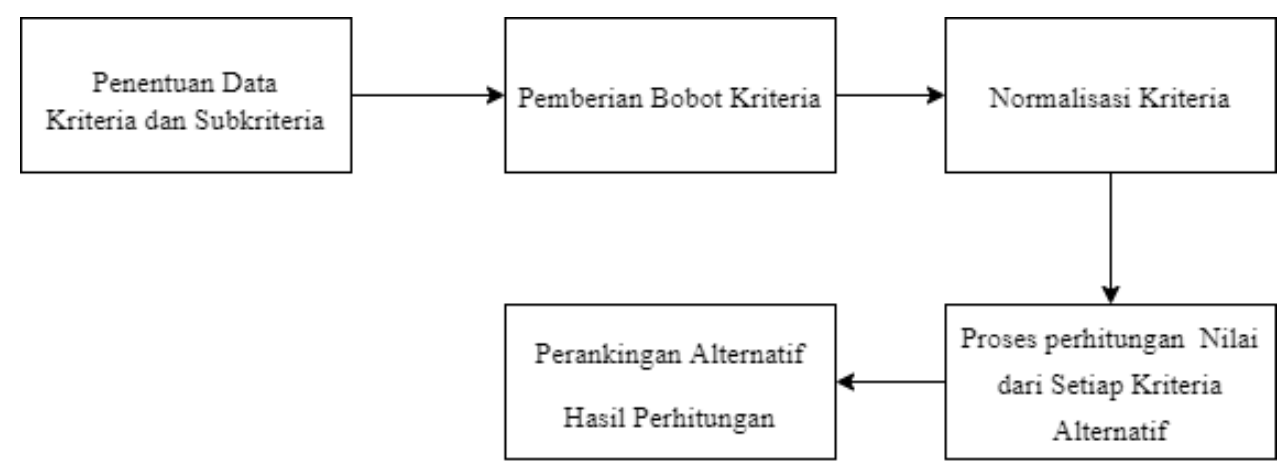

Gambar 2. Tahapan Perhitungan Menggunakan Metode SAW

Berikut proses yang dibutuhkan dalam menerapkan metode SAW[13]-[17], yaitu:

1. Normalisasi Matrik Keputusan

$$
\boldsymbol{r}_{\boldsymbol{i} j}=\left\{\begin{array}{l}
\frac{\boldsymbol{X}_{\boldsymbol{i j}}}{\operatorname{Max} \boldsymbol{X}_{i j}} \text { Jika } j \text { adalah atribut keuntungan (benefit) } \\
\frac{\boldsymbol{M i n}_{i j}}{\boldsymbol{X}_{i j}} \text { Jika } j \text { adalah atribut biaya (cost) }
\end{array}\right.
$$

Keterangan: $\quad$ rij $\quad=$ Rating kinerja ternormalisasi

Max. ij = Nilai maksimum dari setiap baris dan kolom

Min. ij = Nilai minimum dari setiap baris dan kolom

$\mathrm{Xij}=$ Baris dan kolom dari matriks

2. Menghitung Preferensi

$$
V_{i}=\sum_{j=i}^{n} w_{j} r_{i j}
$$

$\begin{array}{lll}\text { Keterangan: } & \mathrm{Vi} & =\text { Nilai akhir dari alternatif } \\ & \mathrm{Wj} & =\text { Bobot yang telah ditentukan } \\ & \mathrm{Rij} & =\text { Normalisasi matriks }\end{array}$

\section{HASIL DAN PEMBAHASAN}

Memilih emiten saham untuk dikoleksi bukanlah hal mudah bagi sebagian investor apalagi emiten tersebut ingin disimpan untuk jangka yang panjang seperti untuk dana pendidikan anak atau untuk dana pensiun di masa depan, hal ini tentukan saja bukanlah merupakan pilihan sekedar pilih tapi harus sesuai dengan perhitungan yang matang agar sesuai dengan tujuan investasi kita di awal. Strategi yang cocok untuk mencapai tujuan tersebut salah satunya adalah dengan menggunakan strategi value investing dimana investor diwajibkan untuk melihat emiten berdasarkan value dari perusahaan tersebut. Dengan menggunakan Sistem Pendukung Keputusan Rekomendasi Emiten Saham Menggunakan Metode Simple Additve Weighting ini kita dapat terbantu dan termudahkan dalam melakukan pemilihan emiten saham dengan diberikannya rekomendasi terbaik dari beberapa alternatif.

\subsection{Data Kriteria dan Subkriteria}

Berikut ini adalah tabel - tabel dari Kriteria yang digunakan: 
Tabel 1. Sub Kriteria PER

\begin{tabular}{ccc}
\hline PER & Keterangan & Bobot \\
\hline$<=15$ & Undervalued & 1 \\
$16-20$ & Normal & 2 \\
$>=21$ & Overvalued & 3 \\
\hline
\end{tabular}

PER (Price to Earning Ratio) adalah rasio keuangan yang digunakan untuk mengukur nilai sebuah perusahaan dengan cara membandingkan harga dari suatu saham dengan laba yang dapat dihasilkannya.

Tabel 2. Sub Kriteria PBV

\begin{tabular}{ccc}
\hline PBV & Keterangan & Bobot \\
\hline$<=1$ & Undervalued & 1 \\
$1,1-2$ & Normal & 2 \\
$>=2,1$ & Overvalued & 3 \\
\hline
\end{tabular}

PBV (Prive to Book Value) adalah rasio keuangan yang digunakan untuk mengukur nilai dari sebuah perusahaan dengan cara membandingkan harga dari suatu saham dengan nilai bukunya.

Tabel 3. Sub Kriteria ROE

\begin{tabular}{ccc}
\hline ROE & Keterangan & Bobot \\
\hline$<=10 \%$ & Tidak Baik & 1 \\
$11 \%-30 \%$ & Baik & 2 \\
$>=31 \%$ & Sangat Baik & 3 \\
\hline
\end{tabular}

ROE (Return On Equity) adalah rasio keuangan yang digunakan untuk mengukur bagaimana sebuah perusahaan dalam menghasilkan laba dengan cara membandingkan laba bersih suatu perusahaan dengan equity atau modal yang dimiliki oleh perusahaan.

Tabel 4. Sub Kriteria EPS

\begin{tabular}{ccc}
\hline EPS & Keterangan & Bobot \\
\hline$<=4 \%$ & Tidak Baik & 1 \\
$5 \%-15 \%$ & Baik & 2 \\
$>=16 \%$ & Sangat Baik & 3 \\
\hline
\end{tabular}

EPS (Earning Per Share) adalah rasio yang digunakan untuk memberikan informasi mengenai laba bersih per setiap lembar saham yang beredar.

Tabel 5. Sub Kriteria DPR

\begin{tabular}{ccc}
\hline DPR & Keterangan & Bobot \\
\hline$<=30 \%$ & Tidak Baik & 1 \\
$31 \%-60 \%$ & Baik & 2 \\
$>=61 \%$ & Sangat Baik & 3 \\
\hline
\end{tabular}

DPR (Dividend Payout Ratio) adalah rasio yang digunakan untuk memberikan informasi mengenai dividend dengan cara membandingkan dividend per lembar saham dengan laba yang dihasilkan per lembar saham.

Tabel 6. Sub Kriteria DY

\begin{tabular}{ccc}
\hline DY & Keterangan & Bobot \\
\hline$<=5 \%$ & Tidak Baik & 1 \\
$>=6 \%$ & Sangat Baik & 3 \\
\hline
\end{tabular}

DY (Dividend Yield) adalah rasio yang digunakan untuk memberikan informasi mengenai dividend yang telah dibagikan oleh perusahaan.

\subsubsection{Bobot Penilaian Kriteria}

Penilaian bobot kriteria ini berdasarkan data kuesioner yang penulis sebarkan :

Tabel 7. Jenis dan Bobot Penilaian Kriteria

\begin{tabular}{ccc}
\hline Kriteria & Jenis Kriteria & Bobot Kriteria \\
\hline PER & Cost & $24 \%$ \\
PBV & Cost & $22 \%$ \\
ROE & Benefit & $16 \%$
\end{tabular}




\begin{tabular}{ccc}
\hline Kriteria & Jenis Kriteria & Bobot Kriteria \\
\hline EPS & Benefit & $16 \%$ \\
DPR & Benefit & $7 \%$ \\
DY & Benefit & $15 \%$ \\
\hline
\end{tabular}

\subsection{Penerapan Metode SAW}

Data yang penulis ambil berdasarkan data kuesioner yang penulis sebarkan :

Tabel 8. Pemberian Nilai Alternatif

\begin{tabular}{ccccccc}
\hline & PER & PBV & ROE & EPS & DPR & DY \\
& C1 & C2 & C3 & C4 & C5 & C6 \\
\hline BBCA & 28,84 & 4,39 & $15,4 \%$ & $1119(3,5 \%)$ & $48,2 \%$ & $1,7 \%$ \\
BBNI & 77,57 & 0,96 & $1,2 \%$ & $75,74(1,2 \%)$ & $25 \%$ & $0,8 \%$ \\
BBRI & 27,77 & 2,62 & $9,5 \%$ & $151,24(3,6 \%)$ & $65,4 \%$ & $2,4 \%$ \\
BMRI & 16,90 & 1,53 & $9,1 \%$ & $366,84(6 \%)$ & $60,1 \%$ & $3,6 \%$ \\
MEGA & 20,02 & 3,31 & $16,5 \%$ & $431,99(5 \%)$ & $69,8 \%$ & $3,5 \%$ \\
\hline
\end{tabular}

Tabel 9. Normalisasi Nilai Alternatif

\begin{tabular}{ccccccc}
\hline & PER & PBV & ROE & EPS & DPR & DY \\
& C1 & C2 & C3 & C4 & C5 & C6 \\
\hline BBCA & 3 & 3 & 2 & 1 & 2 & 1 \\
BBNI & 3 & 1 & 1 & 1 & 1 & 1 \\
BBRI & 3 & 3 & 1 & 1 & 3 & 1 \\
BMRI & 2 & 2 & 1 & 2 & 2 & 1 \\
MEGA & 2 & 3 & 2 & 2 & 3 & 1 \\
\hline
\end{tabular}

Selanjutnya dibuat matriks keputusan agar mempermudahkan menghitung pemilihan keputusan.

$R=\left[\begin{array}{llllll}3 & 3 & 2 & 1 & 2 & 1 \\ 3 & 1 & 1 & 1 & 1 & 1 \\ 3 & 3 & 1 & 1 & 3 & 1 \\ 2 & 2 & 1 & 2 & 2 & 1 \\ 2 & 3 & 2 & 2 & 3 & 1\end{array}\right]$

\section{Tahapan Normalisasi Kriteria}

Melakukan normalisasi kriteria dengan menggunakan rumus dalam metode SAW

a) Kriteria PER(C1)

Kriteria PER merupakan atribut Cost.

$\mathrm{R}_{11}=\frac{\min (3 ; 3 ; 2 ; 2 ; 2)}{3}=\frac{2}{3}=0,66$

$\mathrm{R}_{21}=\frac{\min (3 ; 3 ; 2 ; 2 ; 2)}{3}=\frac{2}{3}=0,66$

$\mathrm{R}_{31}=\frac{\min (3 ; 3 ; 2 ; 2 ; 2)}{3}=\frac{2}{3}=0,66$

$$
\begin{aligned}
& \mathrm{R}_{41}=\frac{\min (3 ; 3 ; 2 ; 2 ; 2)}{2}=\frac{2}{2}=1 \\
& \mathrm{R}_{51}=\frac{\min (3 ; 3 ; 2 ; 2 ; 2)}{2}=\frac{2}{2}=1
\end{aligned}
$$

b) Kriteria $\operatorname{PBV}(\mathrm{C} 2)$

Kriteria PBV merupakan atribut Cost.

$\mathrm{R}_{12}=\frac{\min (3 ; 1 ; 3 ; 2 ; 3)}{3}=\frac{1}{3}=0,33$

$\mathrm{R}_{22}=\frac{\min (3 ; 1 ; 3 ; 2 ; 3)}{1}=\frac{1}{1}=1$

$\mathrm{R}_{42}=\frac{\min (3 ; 1 ; 3 ; 2 ; 3)}{2}=\frac{1}{2}=0,5$

$\mathrm{R}_{32}=\frac{\min (3 ; 1 ; 3 ; 2 ; 3)}{3}=\frac{1}{3}=0,33$

$\mathrm{R}_{52}=\frac{\min (3 ; 1 ; 3 ; 2 ; 3)}{3}=\frac{1}{3}=0,33$

c) Kriteria $\mathrm{ROE}(\mathrm{C} 3)$

Kriteria ROE merupakan atribut Benefit.

$\mathrm{R}_{13}=\frac{2}{\max (2 ; 1 ; 1 ; 1 ; 2)}=\frac{2}{2}=1$

$\mathrm{R}_{23}=\frac{1}{\max (2 ; 1 ; 1 ; 1 ; 2)}=\frac{1}{2}=0,5$

$$
\begin{aligned}
& \mathrm{R}_{43}=\frac{1}{\max (2 ; 1 ; 1 ; 1 ; 2)}=\frac{1}{2}=0,5 \\
& \mathrm{R}_{53}=\frac{2}{\max (2 ; 1 ; 1 ; 1 ; 2)}=\frac{2}{2}=1
\end{aligned}
$$

$\mathrm{R}_{33}=\frac{1}{\max (2 ; 1 ; 1 ; 1 ; 2)}=\frac{1}{2}=0,5$

d) Kriteria $\operatorname{EPS}(\mathrm{C} 4)$ 
Kriteria EPS merupakan atribut Benefit.

$\mathrm{R}_{14}=\frac{1}{\max (1 ; 1 ; 1 ; 2 ; 2)}=\frac{1}{2}=0,5$
$\mathrm{R}_{24}=\frac{1}{\max (1 ; 1 ; 1 ; 2 ; 2)}=\frac{1}{2}=0,5$
$\mathrm{R}_{34}=\frac{1}{\max (1 ; 1 ; 1 ; 2 ; 2)}=\frac{1}{2}=0,5$

e) Kriteria $\operatorname{DPR}(\mathrm{C5})$

Kriteria DPR merupakan atribut Benefit.

$\mathrm{R}_{15}=\frac{2}{\max (2 ; 1 ; 3 ; 2 ; 3)}=\frac{2}{3}=0,66$

$\mathrm{R}_{25}=\frac{1}{\max (2 ; 1 ; 3 ; 2 ; 3)}=\frac{1}{3}=0,33$

$\mathrm{R}_{35}=\frac{3}{\max (2 ; 1 ; 3 ; 2 ; 3)}=\frac{3}{3}=1$

f) Kriteria DY(C6)

Kriteria DY merupakan atribut Benefit.

$\mathrm{R}_{15}=\frac{1}{\max (1 ; 1 ; 1 ; 1 ; 1)}=\frac{1}{1}=1$
$\mathrm{R}_{25}=\frac{1}{\max (1 ; 1 ; 1 ; 1 ; 1)}=\frac{1}{1}=1$
$\mathrm{R}_{35}=\frac{1}{\max (1 ; 1 ; 1 ; 1 ; 1)}=\frac{1}{1}=1$

\section{Melakukan Perangkingan}

Setelah melakukan proses normalisasi selanjutnya akan dilakukan proses perangkingan dengan cara perhitungan preferensi untuk mengetahui hasil akhir dari penilitian. Berikut merupakan proses matriks yang telah di ubah menjadi table preferensi

Tabel 10. Preferensi

\begin{tabular}{cccccccc}
\hline Preferensi & Alternatif & $\begin{array}{c}\text { PER } \\
\text { C1 }\end{array}$ & $\begin{array}{c}\text { PBV } \\
\text { C2 }\end{array}$ & $\begin{array}{c}\text { ROE } \\
\text { C3 }\end{array}$ & $\begin{array}{c}\text { EPS } \\
\text { C4 }\end{array}$ & $\begin{array}{c}\text { DPR } \\
\text { C5 }\end{array}$ & $\begin{array}{c}\text { DY } \\
\text { C6 }\end{array}$ \\
\hline V1 & BBCA & 0,66 & 0,33 & 1 & 0,5 & 0,66 & 1 \\
V2 & BBNI & 0,66 & 1 & 0,5 & 0,5 & 0,33 & 1 \\
V3 & BBRI & 0,66 & 0,33 & 0,5 & 0,5 & 1 & 1 \\
V4 & BMRI & 1 & 0,5 & 0,5 & 1 & 0,66 & 1 \\
V5 & MEGA & 1 & 0,33 & 1 & 1 & 1 & 1 \\
\hline
\end{tabular}

Berikut merupakan bobot penilaian yang telah dikonversi dari persen ke desimal agar mempermudahkan perhitungan.

Tabel 11. Bobot Penilaian Kriteria

\begin{tabular}{cc}
\hline Kriteria & Bobot \\
\hline PER(C1) & $24 \%=0,24$ \\
PBV $(\mathrm{C} 2)$ & $22 \%=0,22$ \\
ROE $(\mathrm{C} 3)$ & $16 \%=0,16$ \\
EPS $(\mathrm{C} 4)$ & $16 \%=0,16$ \\
DPR(C5) & $7 \%=0,07$ \\
DY(C6) & $15 \%=0,15$ \\
\hline
\end{tabular}

Selanjutnya dilakukan perankingan untuk mengetahui hasil akhir dari pemilihan alternatif keputusan.

$\mathrm{V} 1=(0,66 \times 0,24)+(0,33 \times 0,22)+(1 \times 0,16)+(0,5 \times 0,16)+(0,66 \times 0,07)+(1 \times 0,15)=0,6672$

$\mathrm{V} 2=(0,66 \times 0,24)+(1 \times 0,22)+(0,5 \times 0,16)+(0,5 \times 0,16)+(0,33 \times 0,07)+(1 \times 0,15)=0,7115$

$\mathrm{V} 3=(0,66 \times 0,24)+(0,33 \times 0,22)+(0,5 \times 0,16)+(0,5 \times 0,16)+(1,00 \times 0,07)+(1,00 \times 0,15)=0,611$

$\mathrm{V} 4=(1,00 \times 0,24)+(0,5 \times 0,22)+(0,5 \times 0,16)+(1,00 \times 0,16)+(0,66 \times 0,07)+(1,00 \times 0,15)=0,7862$

$\mathrm{V} 5=(1,00 \times 0,24)+(0,33 \times 0,22)+(1,00 \times 0,16)+(1,00 \times 0,16)+(1,00 \times 0,07)+(1,00 \times 0,15)=0,8526$

Tabel 12. Jenis dan Bobot Penilaian Kriteria

\begin{tabular}{ccc}
\hline Ranking & Alternatif & Nilai Preferensi \\
\hline 1 & MEGA & 0,8526 \\
2 & BMRI & 0,7862 \\
3 & BBNI & 0,7115
\end{tabular}




\begin{tabular}{ccc}
\hline Ranking & Alternatif & Nilai Preferensi \\
\hline 4 & BBCA & 0,6672 \\
5 & BBRI & 0,611 \\
\hline
\end{tabular}

Berikut merupakan hasil akhir dari perhitungan dimana ranking tertinggi yaitu saham dengan kode MEGA merupakan saham yang paling di rekomendasikan dari sistem ini dengan nilai preferensi sebesar 0,8526.

\subsection{Implementasi Program}

\section{a. Tampilan Login}

Tampilan Login merupakan tampilan awal ketika pengguna ingin mengakses fitur pada sistem rekomendasi saham. Pengguna akan diminta memasukkan Username dan Password yang sebelumnya sudah didaftarkan pada Registrasi. Ketika Username dan Password berhasil dimasukkan maka pengguna akan diarahkan ke tampilan beranda.
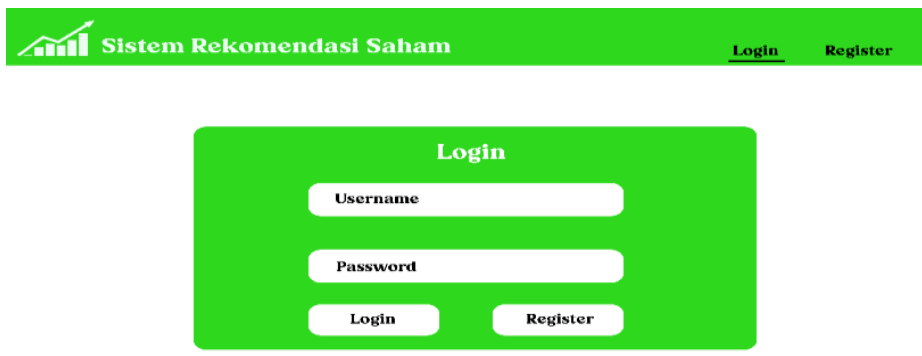

Gambar 3. Tampilan Login

\section{b. Tampilan Beranda}

Tampilan beranda akan muncul setelah pengguna memasukkan Username dan Password pada tampilan beranda terdapat Navigation bar yang terdiri dari Beranda, hasil, dan Logout. Pada tampilan beranda, pengguna akan diminta untuk memasukkan emiten saham yang di inginkan untuk dilakukan analisis untuk rekomendasi saham yang paling cocok untuk pengguna. Jumlah saham yang dimasukkan dapat menyesuaikan dengan kebutuhan pengguna.
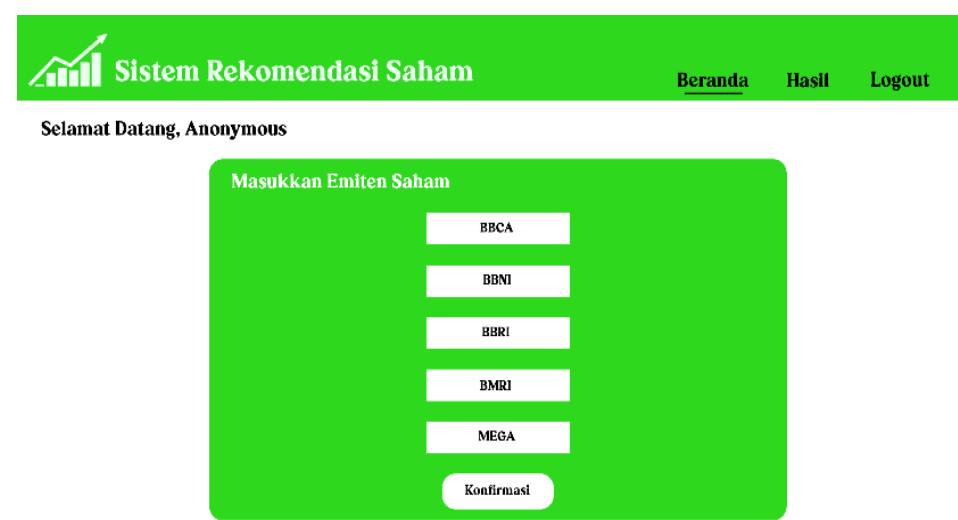

Gambar 4. Tampilan Beranda

\section{c. Tampilan Input Data}

Tampilan masukkan data terdiri dari beberapa kriteria yang telah ditetapkan sehingga pengguna dapat menginputkan nilai dari masing-masing kriteria. Ketika pengguna sudah memasukkan semua nilai dari kriteria maka pengguna dapat menekan tombol konfirmasi dan sistem akan melakukan proses olah data untuk menampilkan hasil.

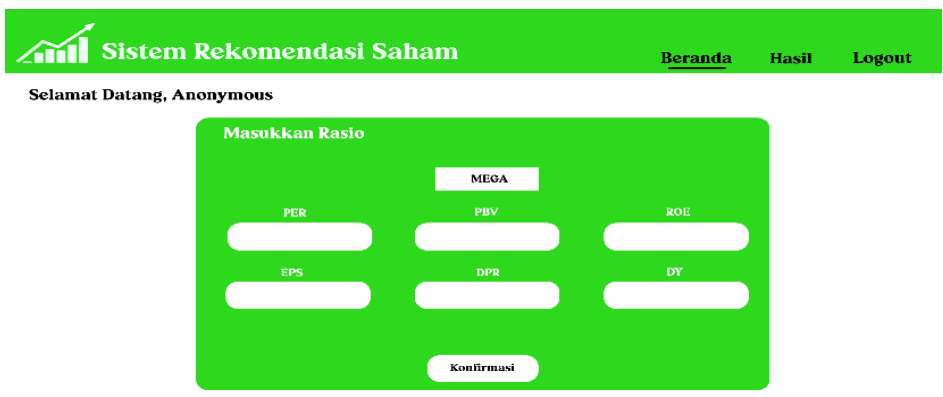

Gambar 5. Tampilan Input Data 


\section{d. Tampilan Hasil}

Tampilan hasil merupakan tampilan akhir dari pengolahan data dimana pengguna akan diberikan rekomendasi saham berdasarkan data yang dimasukkan oleh pengguna. Pada tampilan ini akan dilakukan pemeringkatan mulai dari peringkat yang paling direkomendasikan. Setelah mendapatkan hasilnya pengguna dapat menekan tombol kembali untuk menuju ke beranda.

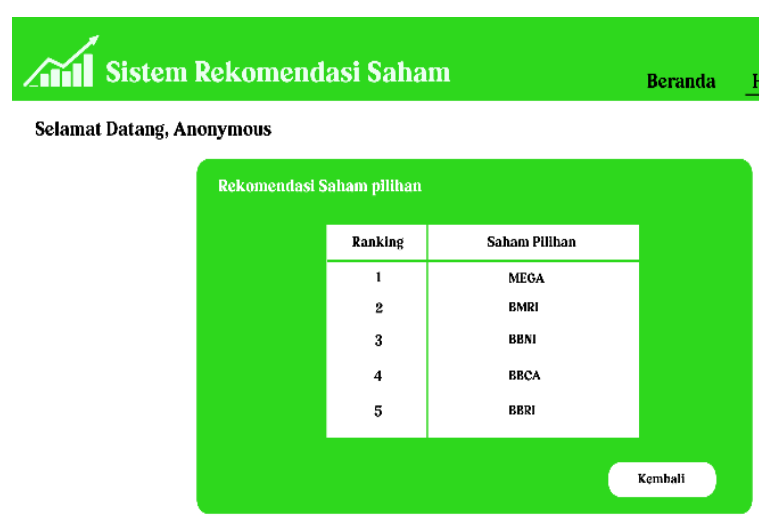

Gambar 6. Tampilan Hasil

\section{KESIMPULAN}

Berdasarkan pembahasan dan hasil dari penilitian ini dapat di simpulkan bahwa pemilihan emiten saham sangat memungkinan dengan menggunakan Sistem Pendukung Keputusan Rekomendasi Emiten Saham Menggunakan Metode Simple Addtive Weighting (SAW), sehingga output yang dihasilkan adalah sebuah rekomendasi emiten saham yang memiliki nilai perangkingan tertinggi yang sekiranya dapat membantu investor dalam melakukan pemilihan saham.

\section{REFERENCES}

[1] A. B. Paksi, E. Utami, and Henderi, "Penerapan SAW-TOPSIS Dalam Analisis Rasio Keuangan," Semin. Nas. Teknol. Inf. dan Multimed., no. 2010, pp. 19-24, 2017.

[2] R. Kusumawardani, A. Solichin, P. T. Informatika, F. T. Informasi, and U. B. Luhur, "Implementasi Metode Simple Additive Weighting ( Saw ) Pada," vol. 1, no. 3, pp. 1-6, 2019.

[3] S. Elviani, R. Simbolon, and S. P. Dewi, "Faktor-Faktor Yang Mempengaruhi Harga Saham Perusahaan Telekomunikasi," J. Ris. Akunt. Multiparadigma, vol. 6, no. 1, pp. 29-39, 2019.

[4] I. Print, K. S. Hermawan, and K. D. Hartomo, "InfoTekJar : Jurnal Nasional Informatika dan Teknologi Jaringan Sistem Pendukung Keputusan Menyeleksi Saham LQ45 untuk Generasi Milenial Menggunakan Metode SAW,” vol. 2, 2021.

[5] T. S. Waruwu and S. Nasution, "Sistem Pendukung Keputusan Pemilihan Investasi Saham Berbasis Web Menggunakan Metode SMART,” J. Mahajana ..., vol. 5, no. 1, 2020.

[6] N. Pranata and T. N. Safitri, "Sistem Pendukung Keputusan Menentukan Kelanjutan Dan Kinerja Keuangan Pada Usaha Produksi Gas Menggunakan Metode Rasio Likuiditas,” J. Sist. Komput. dan ..., vol. 2, pp. 206-210, 2021.

[7] F. M. U. Hasiani, T. Haryanti, R. Rinawati, and L. Kurniawati, "Sistem Pendukung Keputusan Pemilihan Supplier Produk Ritel dengan Metode Analytical Hierarchy Process," Sistemasi, vol. 10, no. 1, p. 139, 2021.

[8] T. Limbong et al., Sistem Pendukung Keputusan: Metode \& Implementasi. Medan: Yayasan Kita Menulis, 2020.

[9] D. Nofriansyah, Multi Criteria Decision Making. Yogyakarta: Deepublish, 2017.

[10] H. Harsiti and H. Aprianti, "Sistem Pendukung Keputusan Pemilihan Smartphone dengan Menerapkan Metode Simple Additive Weighting (SAW)," JSiI (Jurnal Sist. Informasi), vol. 4, pp. 19-24, 2017.

[11] F. Sonata, "Implementasi Metode Simple Additive Weighting (Saw) dengan Proses Fuzzifikasi dalam Penilaian Kinerja Dosen," J. Teknol. Inf. dan Komun., vol. 5, no. 2, pp. 71-80, 2016.

[12] N. C. Resti, "Penerapan Metode Simple Additive Weighting (SAW) pada Sistem Pendukung Keputusan Pemilihan Lokasi untuk Cabang Baru Toko Pakan UD. Indo Multi Fish,” Intensif, vol. 1, no. 2, p. 102, 2017.

[13] R. Y. Simanullang, Melisa, and Mesran, "TIN : Terapan Informatika Nusantara Sistem Pendukung Keputusan Penerima Bantuan Covid-19 Menggunakan Metode Simple Additive Weighting (SAW)," TIN Terap. Inform. Nusant., vol. 1, no. 9, pp. 2-9, 2021

[14] I. J. T. Situmeang, S. Hummairoh, S. M. Harahap, and Mesran, "Application of SAW ( Simple Additive Weighting ) for the Selection of Campus Ambassadors," IJICS (International J. Informatics Comput. Sci., vol. 5, no. 1, pp. 21-28, 2021.

[15] S. H. Sahir, R. Rosmawati, and K. Minan, "Simple Additive Weighting Method to Determining Employee Salary Increase Rate,” Int. J. Sci. Res. Sci. Technol., vol. 3, no. 8, pp. 42-48, 2017.

[16] M. R. Ramadhan, M. K. Nizam, and Mesran, "Penerapan Metode SAW (Simple Additive Weighting) Dalam Pemilihan Siswa-Siswi Berprestasi Pada Sekolah SMK Swasta Mustafa,” TIN Terap. Inform. Nusant., vol. 1, no. 9, pp. 459-471, 2021.

[17] S. K. Simanullang and A. G. Simorangkir, "Sistem Pendukung Keputusan Penerimaan Calon Karyawan Menggunakan Metode Simple Additive Weighting,” TIN Terap. Inform. Nusant., vol. 1, no. 9, pp. 472-478, 2021. 